\title{
Migraine pain: reflections against vasodilatation
}

\author{
Alessandro Panconesi · Maria Letizia Bartolozzi • \\ Leonello Guidi
}

Received: 4 March 2009/Accepted: 9 May 2009/Published online: 5 June 2009

(C) Springer-Verlag 2009

\begin{abstract}
The original Wolff's vascular theory of migraine was supported by the discovery of a class of drugs, the triptans, developed as a selective cephalic vasoconstrictor agents. Even in the neurovascular hypothesis of Moskowitz, that is the neurogenic inflammation of meningeal vessels provoked by peptides released from trigeminal sensory neurons, the vasodilatation provoked by calcitonin gene-related peptide (CGRP) is considered today much more important than oedema. The role of cephalic vasodilatation as a cause of migraine pain was recently sustained by studies showing the therapeutic effect of CGRP receptor antagonists. We discuss the evidence against vasodilatation as migraine pain generator and some findings which we suggest in support of a central (brain) origin of pain.
\end{abstract}

Keywords Migraine - Calcitonin gene-related peptide · Triptans · Vasodilatation P Pain - Migraine pathogenesis

\section{Introduction}

The fundamental question of migraine pathogenesis, until now not clarified, is if pain has a peripheral (vasodilatation) genesis or is a central pain, that is without the need of a stimulus of vascular nociceptors provoked by

A. Panconesi · M. L. Bartolozzi · L. Guidi

Health Authority 11, Empoli (Florence), Italy

A. Panconesi $(\square)$

Via Amedeo Bassi 20, 50025 Montespertoli (FI), Italy

e-mail: a.panconesi@virgilio.it vasodilatation or neurogenic inflammation (NI). The putative peripheral origin of the pain does not exclude that the "primus movens" of migraine attack resides in the brain, for example the cortical spreading depression, which can activate the trigemino-vascular system $[1,2]$. That is, the stimulation of trigeminal nociceptors, due to meningeal vasodilatation induced by peptides substance $P$ (SP) and calcitonin gene-related peptide (CGRP) released by trigeminal peripheral endings during NI provoked by trigeminal stimulation or to meningeal vasodilatation mediated by neuronal autonomic system, is the cause of migraine pain. A general consensus is that innervation of extracerebral blood vessels (meningeal vessels) finds its origin in the superior cervical ganglion (sympathetic innervation) in the sphenopalatine and otic ganglia (parasympathetic innervation) and also in the trigeminal ganglion (sensory innervation) [3, 4]. To date, strategies targeting the autonomic system (anticholinergic antagonists preventing vasodilatation and adrenergic agonists causing constriction) have not proven beneficial in the treatment of migraine [5]. In the last few decades there has been a re-evaluation of the vasodilatation as the cause of migraine pain, that is a sort of revival of the original vascular hypothesis of Wolff [6]. In fact, studies starting from the migraine models of NI, to the discovery of triptans, until the role of CGRP, support vascular (vasodilatation) source of pain [7-10]. In opposition to the vascular theory, there was the Sicuteri' theory, which considers migraine as a central pain, due to a deficiency of the analgesic inhibitory system that is a sort of a deafferentation pain [11-13].

Because one of us (A.P.) has worked with Prof Sicuteri in the past, we would like to comment on the recent findings which have brought the reconsideration of the vascular theory. 


\section{On the triptans}

The excellent and detailed paper of Humphrey [10] concerning the history of the discovery of sumatriptan led us to ask some questions:

1. The first is not a question but an observation: looking at the photograph of the 25 key opinion leaders reunited in the Leeds Castle meeting of 1995 to discuss the sumatriptan mechanism, surprisingly Prof Sicuteri is absent, the scientist of the 5-hydroxytryptamine (5-HT) central theory of migraine, which shows for the first time an alteration of 5-HT metabolism in migraine, which introduces methysergide in the prevention of migraine, which shows that methysergide have 5-HT agonistic activity in man, that is findings leading to the idea that serotonin might have pathophysiological involvement in migraine.

2. The second concerns the statement that sumatriptan, differently from newer triptans, does not normally act centrally because it does not pass the blood brain barrier. Independently from any animal studies, it was evident to clinicians, from the early use of subcutaneous sumatriptan, that this drug provoked in some cases side effects such as dysphoria, sedation, drowsiness, depression, etc., which were clearly central in origin [14-16].

3. The third concerns the Humphrey's statement that he had developed sumatriptan by observation of the studies reporting that ergotamine, 5-HT and also methysergide had beneficial effect in migraine attack probably acting as vasoconstrictors of cephalic vessels. The beneficial effect of 5-HT in migraine attack is, however, uncertain, and also migraine provocation was reported [see 17]. He therefore developed an analogue of 5-HT with selective vasoconstriction on cephalic vessels through $5-\mathrm{HT}_{1}$ receptor subtype, and this was their idea of sumatriptan action. This led to the socalled "triptan revolution" within the pharmaceutical industry and the availability of at least seven triptans in the market place today. Unfortunately, this revolution was not sustained by the population given the low utilization of triptan in the world [18]. However, we have had the pleasure of reading in the Humphrey's paper [10]: "My favourite notion is that central sensitization may arise from a disorder of descending inhibition, which would actually fit with the idea of a hypothetical migraine generator or something that is abnormal in the brain. Also, if there is altered withdrawal of descending inhibition unilaterally, it would explain why there is hemicrania". Therefore, Humphrey today, even though he sustained that painful impulses do originate peripherally from cephalic vessels and that sumatriptan acts almost entirely peripherally [19], moves his attention towards the brain!

\section{On the neurogenic inflammation}

The original hypothesis of Moskowitz based on animal studies stated that the peripheral endings of trigeminal sensory neurons innervating meningeal vessels release peptide SP which provoke plasma protein extravasation (PPE) and vasodilatation, that is NI which in turn stimulates vascular trigeminal nociceptor and then provokes migraine pain. Until now the bulk of studies were performed on this hypothesis. Citing Moskowitz work [20], Hargreaves stated "while there is still debate over the initiating events in migraine, there is no doubt that headache pain arises when the trigeminovascular system became activated causing vasodilatation and activation of the ophthalmic branches of the sensory $\mathrm{V}$ nerve in pain producing meningeal tissues" [5]. There are, however, some findings that doubt the role of NI evidenced in animal studies in the provocation of migraine:

1. Selective and potent inhibitors of PPE in animal models were ineffective in the acute treatment of migraine [see 21, 22].

2. Selective agonists of presynaptic $5-\mathrm{HT}_{1 \mathrm{D}}$ receptors (which would blocks SP release from peripheral trigeminal sensory endings) were ineffective in migraine attack, and there was no correlation between the potency on PPE and antimigraine activity [see 5, 21, 22]. These observations reinforce the view that the antimigraine activity of triptans is dependent upon their interaction with the $5-\mathrm{HT}_{1 \mathrm{~B}}$ receptors, that is through the vasoconstriction.

3. Frequently the doses of antimigraine agents employed in animal studies are higher than the clinical one. Recording the history of ergotamine and dihydroergotamine in migraine, Tfelt-Hansen cited the original study of Moskowitz [23], and affirms that in rats, i.v. ergotamine in doses similar to those used to treat migraine attack and cluster headache, inhibit PPE within the dura mater [24]. The therapeutic i.v. or i.m. doses of ergotamine in migraine is $250 \mu \mathrm{g}$ (about 2.5$5 \mu \mathrm{g} / \mathrm{kg}$ ). The ergotamine doses employed in NI studies was $50 \mu \mathrm{g} / \mathrm{kg}$ [20], that is doses at least ten times higher. Sumatriptan inhibits the release of CGRP from cultured trigeminal neurons but the concentration required was higher than the estimated plasma concentrations in patients receiving the drug for migraine [9].

4. The site of triptans antimigraine action was suggested to be in all the stations of the nociceptive trigeminal 
pathway, starting from meningeal vessel to the thalamus, that is rostral relay of nociceptive trigeminal information $[5,10,19,25,26]$. However, some evidence shows that neither peripheral nor central trigeminovascular neurons are directly inhibited by sumatriptan. Rather the triptans action appears to be exerted through presynaptic $5-\mathrm{HT}_{1 \mathrm{~B} / 1 \mathrm{D}}$ receptors in the dorsal horn to block synaptic transmission between axon terminal of the peripheral trigeminovascular neurons and cell bodies of their central counterparts (trigeminal nucleus caudalis) [27, 28]. The last findings support that the vasoconstrictive effects of sumatriptan and its inhibition of PPE does not play a significant role in the termination of migraine pain. The $5-\mathrm{HT}_{1 \mathrm{D}}$ receptors are localized in fact in trigeminal primary afferent nociceptors, in dense core vescicles, which suggests that they would be available for interaction with triptan only with nociceptive stimulation of sufficient intensity [29]. Triptan receptors are found equally among trigeminal sensory afferents and afferents which innervate the rest of the body [29]. This is at odds with the prevailing view that triptans have selective actions for migraine/cephalic pain. However, there are also studies showing a central antinociceptive effect of triptans. Triptan microinjected in the ventrolateral periaqueductal gray inhibit (probably activating descending pain-modulating pathways) dural, but not facial and corneal nociceptive input [30]. More recently a profound anti-hyperalgesic action of small intrathecal doses, but not 200-fold greater systemic doses, of sumatriptan was found in experimental inflammation in non-cephalic regions [31]. Sumatriptan inhibition of non-trigeminal pain condition involving NI was also described [32]. Data from microinjection studies also suggest that sumatriptan may act within the rostroventral medulla (RVM) to attenuate visceral pain through activation of $5-\mathrm{HT}_{1 \mathrm{~B}}$ receptors [33].

5. Sumatriptan has no inhibitory effect on the discharge of dural nociceptors, but produces a transient discharge of these neurons [28]. This excitatory effect might underlie the initial worsening of headache which was reported after triptan administration [15, 17, 34-36]. It was suggested that this initial headache exacerbation was due to relatively low levels of triptan entering the circulation shortly after administration which activates meningeal nociceptors [34]. It was also sustained that it may simply due to vasodilator effects that occur at lower concentrations than their vasoconstrictor activity as a result of sympathoinhibition [5]. However, small intravenous bolus doses of sumatriptan $(500 \mu \mathrm{g})$ or ergotamine $(50 \mu \mathrm{g})$ provoke a sudden headache exacerbation which is more convincingly due to transitory high blood levels than low levels $[17,36]$. Moreover, the 5-HT doses (4-40 mg) utilized in studies showing migraine provocation [37] seem higher that the ones (2-7.5 mg) utilized in studies showing beneficial effect [38, 39]. Also the superior efficacy of subcutaneous triptans in comparison to the oral form was attributed to the rapid rise in plasma levels ( $T_{\max }$ was $10 \mathrm{~min}$ ) [40].

\section{On the role of CGRP}

Because the NI theory of migraine, specifically PPE, was no longer tenable, the role of CGRP-induced neurogenic vasodilatation was suggested to be of primary importance, that is oedema is less important in comparison to vasodilatation in the stimulation of meningeal nociceptors. Many findings support this theory, such as the CGRP increase in plasma during migraine attack with normalization after sumatriptan concomitantly with alleviation of headache, the induction of migraine-like headache by intravenous CGRP and the efficacy of CGRP receptor antagonists [see 9, 21, 41, 42]. In particular, three fundamental findings sustain this interpretation:

1. A substantial increase of CGRP levels in jugular vein but not in peripheral vein in migraine attack [43]. Even in nitroglycerin (NTG)-induced migraine attack an increase of plasma CGRP was found, but not in immediate headache or in subjects without migraine attack [44].

2. The CGRP infusion $(2 \mu \mathrm{g} / \mathrm{min} / 20 \mathrm{~min})$ provokes in migraine subjects immediate and delayed (1-12 h, median 5) headache, sometimes with migraine-like characteristics, with similar latency but lesser intensity than that provoked by glyceryl trinitrate (GTN) and histamine. It was argued that nitric oxide (NO) may be a common mediator of GTN, histamine and CGRPinduced headache; otherwise, CGRP may be the common mediator of GTN, histamine and CGRP [45].

3. The CGRP receptors antagonists were effective in migraine attack with efficacy comparable to triptans $[46,47]$.

However, much evidence does not sustain the role of CGRP vasodilatation:

1. Using an intra-patient comparison design, CGRP was not found to increase in external jugular vein and in peripheral vein during migraine attack in comparison to attack-free period [48]. Previous studies compared CGRP blood levels during attack with those of control subjects, and the results can be affected by a large inter-individual variation of CGRP levels. 
2. The CGRP infusion $(1.5 \mu \mathrm{g} / \mathrm{min} / 20 \mathrm{~min})$ in healthy subjects induces mild immediate and delayed headache, and dilatation of middle cerebral artery (MCA) and of superficial temporal artery (STA). The CGRP antagonist olcegepant prevents the headache and STA dilatation, but not that of MCA, suggesting a extracerebral action. However, at the end of infusion, the CGRP plasma concentration was increased 4-5 times from baseline, and is higher than that found in spontaneous migraine attack [49].

3. There were no differences in the degree of vasodilatation of MCA (moreover mild) and of peripheral arteries between migraine and healthy subjects [5052].

4. There were no differences in immediate and delayed headache (of mild intensity and low frequency) and in the degree of MCA and STA vasodilatation between familial hemiplegic migraine and healthy subjects [53].

5. Recently, with sensitive and non-invasive magnetic resonance angiography (3T MRA), it was shown that during migraine induced by NTG, the diameter of intracerebral (internal carotid, middle and posterior cerebral, basilar) and extracerebral (mean meningeal, external carotid) arteries were not different from baseline, and there was no difference between headache and non-headache sides. Moreover, there was no change in basilar and internal carotid artery blood flow during NTG infusion or migraine. These findings suggest that migraine attack is not associated with vasodilatation of cerebral or meningeal vessels [54].

6. Many studies show that different vasoactive neurotransmitters found in perivascular nerve fibres and

Table 1 Headache (median headache score) and vasodilation of middle cerebral artery (MCA) and superficial temporal artery (STA) provoked by vasodilator drugs in healthy subjects (HS) and migraine patients (MS)

\begin{tabular}{llll}
\hline & MCA & STA & Headache \\
\hline GTN [55, 56] MS, HS & Yes & Yes & 5.0 (MS), 2.0 (HS) \\
Sildenafil [57, 58] MS, HS & No & No & $6.5(\mathrm{MS}), 2.5$ (HS) \\
Dypiridamole [59] MS, HS & Yes & $?$ & 2.0 \\
CGRP [45] MS & Yes & Yes & 4.0 \\
Cilostazol [60] HS & Yes & Yes & 3.5 \\
Adenosine [61] HS & No & Yes & 1.5 \\
VIP [62] MS & Yes & Yes & No \\
PACAP38 [63] HS, MS & Yes & Yes & $3.5(\mathrm{HS}), 2.5$ (MS) \\
Carbachol [64] HS & Yes & Yes & 1.0 \\
Adrenomedullin [65] MS & No & Yes & No \\
Istamine [66] MS & Yes & Yes & 5.0 \\
\hline
\end{tabular}

other vasodilating agents may trigger headache, but with some contradictions (Table 1). The immediate dilatation of the MCA seen after treatment with GTN, histamine, CGRP, dipyridamole, has been considered to play a causative role in the induction of migraine attacks [55, 56]. Dipyridamole and CGRP (both cAMP-elevating compounds) induce migraine less frequently than GTN and sildenafil [45, 55, 56, 58, 59]. However sildenafil, which is more effective migraine inducing agent than CGRP and probably also than histamine, does not induce cephalic vasodilatation [58]. It was suggested that parasympathetic nervous system may be involved in the initiation and maintenance of migraine attacks [67]. However, vasoactive intestinal peptide (VIP), a neurotransmitter of cerebral parasympathetic perivascular nerve fibres, provokes marked cephalic vasodilatation but not migraine, providing further evidence against a purely vascular origin of migraine [62]. Even the moderate degree of dilation after cilostazol or dipyridamole makes a simple mechanical dilation an unlikely source of pain $[60,61]$. Thus the dilatation of cephalic arteries seems unlikely to be the direct cause of the migrainelike attacks occurring hours after the infusion of vasodilator drugs.

7. Sumatriptan inhibits CGRP release from stimulated trigeminal neurons but not in baseline conditions [9, 68]. Animal studies show that sumatriptan does not inhibit CGRP vasodilatation [32, 69, 70]. Neither dural nor systemic administration of CGRP, at doses that evoked dural vasodilatation, had a detectable effect on discharge of dural nociceptors, which are also subjected to rapid desensitization [28]. Other evidence for a possible weak action on CGRP in the periphery are the brief (7-10 min) plasma half-life of GGRP in humans [21] and tachyphylaxis of the vascular responses [71]. Even the excitation of trigeminal brainstem neurons by the application in the meningeal subarachnoid space of a mixture of inflammatory mediators was subjected to tachyphylaxis [72].

These findings not only fail to support the vasodilatation theory but also would potentially seem to be at odds with large body of evidence on the role of GCRP in headache and suggest an action as a central neurotransmitter [28]. A possible central action of CGRP and CGRP antagonists on second-order trigeminal neurons was discussed [73].

Considering a possible role of CGRP-induced vasodilatation in migraine pathogenesis, because migraine patients are not more sensitive to vasodilating action of CGRP and other vasodilating agents in comparison to healthy subjects $[50-52,62,63]$, the induction of migraine attack must be due to a less inhibition or to a facilitation by 
pain modulating system of sensory transmission. The last hypothesis could explain the fact that vascular cerebral disease and vasodilating agents (NO, histamine, CGRP, etc.) can provoke headache/migraine more frequently in migraine patients than in healthy subjects.

As pointed by Moskowitz [1], there are two hypothesis regarding the pathogenesis of migraine. One is that migraine originates in the cortex and the other that originates in the brainstem. In the first case the cortical spreading depression directly stimulate the trigeminal nerves. In the other case, an abnormal activity in brainstem nuclei (locus coeruleus, raphe nucleus and periaqueductal gray) could induce pain in two ways: (1) by a disinhibition of trigeminal neurons within the trigeminal nucleus, allowing this neurons to fire even in the absence of incoming pain signals from the meninges or blood vessels (that is without a role for vasodilatation) and (2) by triggering spreading depression.

But the key question is which way provokes meningeal vasodilatation. That is, the activation of trigeminovascular system, possibly also by cortical spreeding depression [1], could provoke CGRP release from sensory neurons which dilate meningeal vessels, which in turn will stimulate meningeal nociceptors and then the transmission of pain through trigeminal pathway until the cortex. Otherwise, the activation of trigeminal neurons could provoke vasodilatation via brainstem trigeminoautonomic arc reflex activation of sphenopalatine ganglion, which leads to perivascular release of dilatators such as acetylcholine, VIP and NO. Anyway, the activation of trigeminal neurons must send the signal in the periphery to provoke vasodilatation which in its turn will stimulate meningeal trigeminal nociceptors to transmit by the same way where the impulse originates the painful sensation. In this view, it was also suggested that multiple migraine triggers activate different brain areas which activate parasympathetic neurons and through vasodilatation the meningeal nociceptors; the trigeminovascular pathway in turn can activate the same brain areas that have triggered its own activity in the first place [67]. This seems an illogical and uneconomic way to provoke migraine pain. It is also difficult to think that a brain stimulus provokes a cephalic dilatation and that a simple dilatation provokes itself the storm of symptoms of migraine attack. We think that the activation of peripheral trigeminal sensory neurons (possibly by the disorder of descending inhibition or also from cortical spreeding depression) could send directly the stimulus to higher centers of pain, without the necessity to provoke vasodilatation, which in this case could play a secondary role (as a cause of throbbing or of initial worsening of pain produced by triptans $[5,27])$.

\section{On the pain modulatory system}

An involvement of 5-HT pain modulating system was theorized in migraine pathogenesis: a reduced descending inhibition or an enhanced descending facilitation was suggested [see 36].

The RVM in the brainstem which contains nucleus raphe magnus (NRM) and the adjacent reticular formation is an important relay site for integrating descending influences on the spinal cord and trigeminal nucleus caudalis. Many of the midbrain areas that are involved in fear, anxiety, mood and autonomic responses are contacted by pathways that are activated by painful stimuli. There is a growing body of evidence suggesting that descending pathways are not exclusively inhibitory, but also include excitatory actions. In fact, in the RVM there are three functional cell classes: the ON cells (inhibited by opioids) which facilitate nociception, the OFF cells (excited by opioids) which inhibit nociception, both non-serotonergic (but at least a proportion of ON cells are likely to contains 5-HT), and a population of serotonergic cell unresponsive to noxious stimulation and opioids, which may play a permissive role. Tonic activation of 5-HT-mediated and non-5HT-mediated brainstem facilitatory influences contributes to the development of central sensitization in neurophatic pain (but not in the experimental inflammatory pain) $[74,75]$. Although not clarified, 5-HT can produce antinociceptive and pronociceptive effects depending on the receptors it acts on the dorsal horn. Activation of 5- $\mathrm{HT}_{1}$ receptors exert antinociceptive effect: postsynaptic $5-\mathrm{HT}_{1 \mathrm{~A}}$ receptors inhibit the excitability of spinotalamic neurons and excitatory interneurons, whereas presynaptic $5-\mathrm{HT}_{1 \mathrm{~B} / \mathrm{D}}$ inhibit neurotransmitter release from primary nociceptive afferents. The pronociceptive effect appears mediated by $5-\mathrm{HT}_{2}$ and particularly $5-\mathrm{HT}_{3}$ receptors. The $5-\mathrm{HT}_{3}$ receptors increase neurotransmitter release from primary nociceptive afferents, whereas postsynaptic $5-\mathrm{HT}_{3}$ receptors increase excitability of spinothalamic neurons [76]. Different hyperalgesic states including acute inflammation, acute opioid withdrawal and models of systemic illness and acute stress are associated with an increase of ON cell firing and suppression of OFF-cell disharge [77].

Recent interesting findings show that mice genetically lacking in central serotonergic neurons showed normal visceral pain but exhibited enhanced inflammatory pain. Moreover, the analgesic effect of several antidepressant drugs were abolished or greatly attenuated [78]. These mice also exhibited reduced analgesic effects to $\mu$ and $\delta$ opioid receptor agonists, providing genetic evidence in support of the view that the central serotonergic system is a key component of supraspinal pain modulatory circuitry mediating opioid analgesia [79]. 
These pharmacological responses of the genetically modified mice, well concord with those of migraine patients. In fact, selective serotonin reuptake inhibitors have no therapeutic activity in migraine [80]. Moreover, migraine patients $[13,81,82]$ and also chronic daily headache patients [83] were considered poorly responsive to opioid drugs and more sensitive to their side effects [82, 84]. Also, mepheridine was less effective than other antimigraine drugs such as dihydroergotamine and antiemetics, and in many trials it was co-administered with antihistamines which may enhance its efficacy [85]. Curiously, it was shown that a genetic variation may be responsible of the intolerable side effects or inadequate analgesia produced by morphine in $10-30 \%$ of cancer patients [86]. A similar genetic alteration could be present in migraine patients? Or, alternatively, have the unresponsive cancer patients also suffered for migraine?

Other findings sustain a hypofunction of 5-HT cerebral system in migraine patients. In fact, the most reproducible and ubiquitous abnormality of migraineurs's brain is a lack of habituation in neuronal information processing with normalization during migraine attack. This cortical hyperresponsivity was suggested to be due to a dysrhythmic thalamo-cortical activity due to inadequate monoaminergic (serotonergic) control [87]. Normalization of habituation during migraine attack could be induced by the ictal activation of rostral brainstem which has been demonstrated by PET scanning [88-90]. Recently, in support of this interpretation, it was demonstrated that brain serotonin synthesis increases during the migraine attack [91]. Moreover, a PET study has shown an increase of 5-HT $\mathrm{HA}_{1 \mathrm{~A}}$ receptors binding in cortical and limbic area during interictal period in migraine patients, possibly due to low brain 5-HT levels [92]. Lack of habituation was evidenced also utilizing laser-evoked noxious stimuli in cephalic and extra-cephalic territory [93]. That habituation of pain involves the antinociceptive system (notably the cingulated cortex) which may trigger down-stream, potentially opioid-dependent mechanism, must be underlined [94].

A direct evidence for specific functional changes in the brainstem during the interictal migraine period was recently provided. In fact, it was reported that nucleus cuneiformis, a component of brainstem pain modulatory circuits which contains both "OFF and "ON" cells, appears to be hypofunctional in migraine patients, possibly contributing to hyperexcitability of trigeminovascular neurons in migraineurs by either reduced descending inhibition or enhanced descending facilitation [95].

\section{Conclusion}

Sicuteri's 5-HT central theory stated that migraine pain originates from an alteration, apparently functional in nature, of the neuraxial pain transmission. Pain arises without any stimulation of nociceptors by vasodilatation, but results from an automatism of the nociceptive system, due to a failure of descending anti-nociceptive 5-HT/ opioidergic system [11, 12]; a theory subsequently interpreted as "functional deafferentation" [13]. Analogies between migraine and sensory deafferentation have been recently proposed once again [96].

Recently, Goadsby [97] sustains that "the basis of the problem is likely to be abnormal central processing of normal sensory signal" that is "a disturbance of subcortical sensory modulation systems". Moreover, it was suggested that migraine triggers cause cortical activation, which disinhibits trigeminovascular sensation through brainstem nuclei (NRM) involving a serotonergic mechanisms. The pain signal was suggested as a "false alarm" occasioned by some defect in pain perception or modulation [98].

In opposition, some sustained that migraine may have a vascular basis in at least some individuals and to presume that migraine is always generated from within the central nervous system "is naïve at best and unscientific at worst [99]" and "flies in the face of common sense, clinical observation and existing scientific data" [100]. On the other hand, many arguments against pure vasodilation as migraine generator are reported [101].

Without citing scientific data, previously referred to, if we debate using common sense, this allows us to submit three fundamental questions:

1. Do other types of vasodilator pain exist other than migraine? All data which supports the vascular origin of migraine pain shows ischaemic, but not vasodilatory, diseases. In nature, vascular pain is generally caused by ischaemic diseases and we cannot think of any pain caused purely by vasodilatation, which generally relieves pain.

2. Because in extracranial and meningeal arteries (other than in brain circulation: circle of Willis) there are anastomose ipsi- and contralaterally [102], are we convinced that a strictly hemilateral migraine can be explained by hemilateral vasodilatation? How can it be explained that some migraine subjects always have attacks on the same side? How can we explain the shift of pain from one side to the other during the same attack?

3. Are we convinced that chronic daily headache (chronic migraine) can be explained by persistent vasodilatation? It is true that chronic migraine pain can be maintained by the central sensitization, but taking this for granted we consequently maintain that it could be generated in the brain without the need of vascular dilatation.

In conclusion, we think that spontaneous migraine pain may be produced and maintained in the brain and that 
vasodilatation is a epiphenomenon. Nevertheless, we believe possible that a transitory vasodilator effect (as that provoked by some drugs) can trigger undefined central mechanisms which are able to provoke migraine attack, as any migraine trigger such as stress, hormonal variations, etc.. This interpretation may explain even the delayed headache provoked by vasodilator agents, at a time when vasodilatation has ended.

Conflict of interest None.

\section{References}

1. Moskowitz MA (2007) Pathophysiology of headache-past and present. Headache 27(Suppl 1):S58-S63. doi:10.1111/j.15264610.2007.00678.x

2. Parsons AA, Strijbos PJ (2003) The neuronal versus vascular hypothesis of migraine and cortical spreading depression. Curr Opin Pharmacol 3:73-77. doi:10.1016/S1471-4892(02)00016-4

3. Edvinsson L, Hamel E (2002) Perivascular nerves in brain vessels. In: Edvinsson L, Krause DN (eds) Cerebral blood flow and metabolism, 2nd edn. Lippincott Williams \& Wilkins, Philadelphia, pp 43-67

4. Edvinsson L, Uddman R (2005) Neurobiology in primary headaches. Brain Res Rev 48:438-456. doi:10.1016/j.brainresrev. 2004.09.007

5. Hargreaves R (2007) New migraine and pain research. Headache 47(Suppl 1):S26-S43. doi:10.1111/j.1526-4610.2006. 00675.x

6. Wolff HG (1963) Headache and other head pain. Oxford University Press, New York

7. Moskowitz MA (1984) The neurobiology of vascular head pain. Ann Neurol 16:157-186. doi:10.1002/ana.410160202

8. Goadsby PJ, Edvinsson L, Ekman R (1988) Release of vasoactive peptides in the extracerebral circulation of humans and the cat during activation of the trigeminovascular system. Ann Neurol 23:193-196. doi:10.1002/ana.410230214

9. Durham PL (2006) Calcitonin gene-related peptide (CGRP) and migraine. Headache 46(Suppl 1):S3-S8. doi:10.1111/j.15264610.2006.00483.x

10. Humphrey PPA (2007) The discovery of a new drug class for the acute treatment of migraine. Headache 47(Suppl 1):S10-S19. doi:10.1111/j.1526-4610.2007.00672.x

11. Sicuteri F (1976) Hypothesis: migraine, a central biochemical dysnociception. Headache 16:145-159. doi:10.1111/j.15264610.1976.hed 1604145.x

12. Sicuteri F, Del Bianco PL, Anselmi B (1979) Morphine abstinence and serotonin supersensitivity in man: analogies with the mechanism of migraine? Psychopharmacology 65:205-209. doi: 10.1007/BF00433050

13. Sicuteri F (1987) Quasi-phantom head pain from functional deafferentation. Clin J Pain 3:63-80. doi:10.1097/00002508198703020-00001

14. Sullivan JT, Preston KL, Testa MP, Busch M, Jasinski DR (1992) Psychoactivity and abuse potential of sumatriptan. Clin Pharmacol Ther 52:635-642

15. Panconesi A, Franchi G, Anselmi B, Curradi C (1994) On the mechanism of sumatriptan side effects. In: Fusco BM, Giacovazzo $M$ (eds) Unilateral headache: focus on recent advances. RD Editori, Rome, pp 111-116
16. Dodick DW, Martin V (2004) Triptans and CNS side-effects: pharmacokinetic and metabolic mechanism. Cephalalgia 24:417-424. doi:10.1111/j.1468-2982.2004.00694.x

17. Panconesi A, Sicuteri R (1997) Headache induced by serotonergic agonists-a key to the interpretation of migraine pathogenesis? Cephalalgia 17:3-14. doi:10.1046/j.1468-2982.1997. 1701003.x

18. Panconesi A, Pavone E, Vacca F, Vaiani M, Banfi R (2008) Triptans in the Italian population: a drug utilization study and a literature review. J Headache Pain 9:71-76. doi:10.1007/s10194008-0020-3

19. Humphrey PPA (2008) The discovery and development of the triptans, a major therapeutic breakthrough. Headache 48:685687. doi:10.1111/j.1526-4610.2008.01097.x

20. Moskowitz MA (1991) The visceral organ brain: implications for the pathophysiology of vascular head pain. Neurology 41:182-186

21. Geppetti P, Capone JG, Trevisani M, Nicoletti P, Zagli G, Tola MR (2005) CGRP and migraine: neurogenic inflammation revisited. J Headache Pain 6:61-70. doi:10.1007/s10194-0050153-6

22. Villalon CM, Centurion D (2007) Cardiovascular responses produced by 5 -hydroxytryptamine: a pharmacological update on the receptors/mechanisms involved and therapeutic implications. Naunyn-Schmiedeberg's Arch Pharmacol 376:45-63. doi: 10.1007/s00210-007-0179-1

23. Markowitz S, Saito K, Moskowitz MA (1988) Neurogenically mediated plasma extravasation in dura mater: effect of ergot alkaloids. A possible mechanism of action in vascular headache. Cephalalgia 8:83-91. doi:10.1046/j.1468-2982.1988.0802083.x

24. Tfelt-Hansen PC, Koehler PJ (2008) History of the use of ergotamine and dihydroergotamine in migraine from 1906 and onward. Cephalalgia 28:877-886. doi:10.1111/j.1468-2982. 2008.01578.x

25. Shields KG, Goadsby PJ (2006) Serotonin receptors modulate trigeminovascular responses in ventroposteromedial nucleus of thalamus: a migraine target? Neurobiol Dis 23:491-501. doi: 10.1016/j.nbd.2006.04.003

26. Jeong H-J, Chenu D, Johnson EE, Connor M, Vaughan CW (2008) Sumatriptan inhibits synaptic transmission in the rat midbrain periaqueductal grey. Mol Pain. doi:10.1186/17448069-4-54

27. Levy D, Jakubowski M, Burstein R (2004) Disruption of communication between peripheral and central trigeminovascular neurons mediates the antimigraine action of $5 \mathrm{HT}_{1 \mathrm{~B} / 1 \mathrm{D}}$ receptor agonists. Proc Natl Acad Sci USA 101:4274-4279. doi: 10.1073/pnas.0306147101

28. Strassman AM, Levy D (2006) Response properties of dural nociceptors in relation to headache. J Neurophysiol 95:12981306. doi:10.1152/jn.01293.2005

29. Potrebic S, Ahn AH, Skinner K, Fields HL, Basbaum AI (2003) Peptidergic nociceptors of both trigeminal and dorsal root ganglia express serotonin 1D receptors: implications for the selective antimigraine action of triptans. J Neurosci 23:10988-10997

30. Bartsch T, Knight YE, Goadsby PJ (2004) Activation of $5-\mathrm{HT}_{1 \mathrm{~B} / 1 \mathrm{D}}$ receptor in the periaqueductal gray inhibits nociception. Ann Neurol 56:371-381. doi:10.1002/ana.20193

31. Nikai T, Basbaum AI, Ahn AH (2008) Profound reduction of somatic and visceral pain in mice by intrathecal administration of the anti-migraine drug, sumatriptan. Pain 139:533-540. doi: 10.1016/j.pain.2008.06.002

32. Carmichael NME, Charlton MP, Dostrovsky JO (2008) Activation of the $5-\mathrm{HT}_{1 \mathrm{~B} / \mathrm{D}}$ receptor reduces hindlimb neurogenic inflammation caused by sensory nerve stimulation and capsaicin. Pain 134:97-105. doi:10.1016/j.pain.2007.03.037 
33. Vera-Portocarrero LP, Ossipov MH, King T, Porreca F (2008) Reversal of inflammatory and noninflammatory visceral pain by central or peripheral actions of sumatriptan. Gastroenterology 135:1369-1378. doi:10.1053/j.gastro.2008.06.085

34. Burstein R, Jakubowski M, Levy D (2005) Anti-migraine action of triptans is preceded by transient aggravation of headache caused by activation of meningeal nociceptors. Pain 115:21-28. doi:10.1016/j.pain.2005.01.027

35. Visser WH, de Vriend RH, Jaspers NH, Ferrari MD (1996) Sumatriptan-nonresponders: a survey in 366 migraine patients. Headache 36:471-475. doi:10.1046/j.1526-4610.1996. 3608471.x

36. Panconesi A (2008) Serotonin and migraine: a reconsideration of the central theory. J Headache Pain 9:267-276. doi:10.1007/ s10194-008-0058-2

37. Ostfeld AM (1960) Migraine headache: its physiology and biochemistry. JAMA 174:1188-1190

38. Kimball RW, Friedman AP, Vallejo E (1960) Effect of serotonin in migraine patients. Neurology 10:107-111

39. Anthony M, Hinterberger H, Lance JW (1967) Plasma serotonin in migraine and stress. Arch Neurol 16:544-552

40. Tfelt-Hansen P (2007) Parenteral vs. oral sumatriptan and naratriptan: plasma levels and efficacy in migraine: a comment. J Headache Pain 8:273-276. doi:10.1007/s10194-007-0411-x

41. Edvinsson L (2004) Blockade of CGRP receptors in the intracranial vasculature: a new target in the treatment of headache. Cephalalgia 24:611-622. doi:10.1111/j.1468-2982.2003.00719.x

42. Link AS, Kuris A, Edvinsson L (2008) Treatment of migraine attacks based on the interaction with the trigemino-cerebrovascular system. J Headache Pain 9:5-12. doi:10.1007/ s10194-008-0011-4

43. Goadsby PJ, Edvinsson L, Ekman R (1990) Vasoactive peptide release in the extracerebral circulation of humans during migraine headache. Ann Neurol 28:183-187. doi:10.1002/ana. 410280213

44. Juhasz G, Zsombok T, Modos EA, Olajos S, Jakab B, Nemeth J, Szolcsanyi J, Vitrai J, Bagdy G (2003) NO-induced migraine attack: strong increase in plasma calcitonin gene-related peptide (CGRP) concentration and negative correlation with platelet serotonin release. Pain 106:461-470. doi:10.1016/j.pain.2003. 09.008

45. Lassen LH, Haderslev PA, Jacobsen VB, Iversen HK, Sperling $\mathrm{B}$, Olesen J (2002) CGRP may play a causative role in migraine. Cephalalgia 22:54-61. doi:10.1046/j.1468-2982.2002.00310.x

46. Olesen J, Diener HC, Husstedt IW, Goadsby PJ, Hall D, Meier U, Pollentier S, Lesko LM (2004) Calcitonin gene-related peptide receptor antagonist BIBN 4096 BS for the acute treatment of migraine. N Engl J Med 350:1104-1110. doi:10.1056/ NEJMoa030505

47. Ho TW, Mannix LK, Fan X, Assaid C, Furtek C, Jones CJ, Lines CR, Rapoport AM (2008) Randomized controlled trial of an oral CGRP receptor antagonist, MK-0974, in acute treatment of migraine. Neurology 70:1304-1312. doi:10.1212/01.WNL. 0000286940.29755 .61

48. Tvedskov JF, Lipka K, Ashina M, Iversen HK, Schifter S, Olesen J (2005) No increase of calcitonin gene-related peptide in jugular blood during migraine. Ann Neurol 58:561-568. doi: 10.1002/ana.20605

49. Petersen KA, Lassen LH, Birk S, Lesko L, Olesen J (2005) BIBN4096BS antagonizes human a-calcitonin gene related peptide-induced headache and extracerebral artery dilatation. Clin Pharmacol Ther 77:202-213. doi:10.1016/j.clpt.2004. 10.001

50. Lassen LH, Jacobsen VB, Haderslev PA, Sperling B, Iversen HK, Olesen J, Tfelt-Hansen P (2008) Involvement of calcitonin gene-related peptide in migraine: regional cerebral blood flow and blood flow velocity in migraine patients. J Headache Pain 9:151-157. doi:10.1007/s10194-008-0036-8

51. Edvinsson ML, Edvinsson L (2008) Comparison of CGRP and NO responses in the human peripheral microcirculation of migraine and control subjects. Cephalalgia 28:563-566. doi: 10.1111/j.1468-2982.2008.01558.x

52. de Hoon JN, Smits P, Troost J, Struijker-Boudier HA, Van Bortel LM (2006) Forearm vascular response to nitric oxide and calcitonin gene-related peptide: comparison between migraine patients and control subjects. Cephalalgia 26:56-63. doi: 10.1111/j.1468-2982.2005.00993.x

53. Hansen JM, Thomsen LL, Olesen J, Ashina M (2008) Calcitonin gene related peptide does not cause the familial hemiplegic migraine phenotype. Neurology 71:841-847. doi:10.1212/01. wnl.0000325482.64106.3f

54. Schoonman GG, van der Grond J, Kortmann C, van der Geest RJ, Terwindt GM, Ferrari MD (2008) Migraine headache is not associated with cerebral or meningeal vasodilation-a $3 \mathrm{~T}$ magnetic resonance angiography study. Brain 131:2192-2200. doi:10.1093/brain/awn094

55. Olesen J, Iversen HK, Thomsen LL (1993) Nitric oxide supersensitivity: a possible molecular mechanism of migraine pain. NeuroReport 4:1027-1030

56. Olesen $\mathbf{J}$ (2008) The role of nitric oxide (NO) in migraine, tension-type headache and cluster headache. Pharmacol Ther 120:157-171. doi:10.1016/j.pharmthera.2008.08.003

57. Kruuse C, Thomsen LL, Jacobsen TB, Olesen J (2002) The phosphodiesterase 5 inhibitor sildenafil has no effect on cerebral blood flow or blood velocity, but nevertheless induces headache in healthy subjects. J Cereb Blood Flow Metab 22:1124-1131. doi:10.1097/00004647-200209000-00010

58. Kruuse C, Thomsen LL, Birk S, Olesen J (2003) Migraine can be induced by sildenafil without changes in middle cerebral artery diameter. Brain 126:241-247. doi:10.1093/brain/awg009

59. Kruuse C, Lassen LH, Iversen HK, Oestergaard S, Olesen J (2006) Dipyridamole may induce migraine in patients with migraine without aura. Cephalalgia 26:925-933. doi:10.1111/j. 1468-2982.2006.01137.x

60. Birk S, Kruuse C, Petersen KA, Tfelt-Hansen P, Olesen J (2006) The headache-inducing effect of cilostazol in human volunteers. Cephalalgia 26:1304-1309. doi:10.1111/j.1468-2982.2006. 01218.x

61. Birk S, Petersen KA, Kruuse C, Guieu R, Jonassen O, Eisert W, Olesen J (2005) The effect of circulating adenosine on cerebral haemodynamics and headache generation in healthy subjects. Cephalalgia 25:369-377. doi:10.1111/j.1468-2982.2005.00867.x

62. Rahmann A, Wienecke T, Hansen JM, Fahrenkrug J, Olesen J, Ashina M (2008) Vasoactive intestinal peptide causes marked cephalic vasodilation, but does not induce migraine. Cephalalgia 28:226-236. doi:10.1111/j.1468-2982.2007.01497.x

63. Schytz HW, Birk S, Wienecke T, Kruuse C, Olesen J, Ashina M (2009) PACAP38 induces migraine-like attacks in patients with migraine without aura. Brain 132:16-25. doi:10.1093/brain/ awn307

64. Schytz HW, Wienecke T, Oturai PS, Olesen J, Ashina M (2009) The cholinomimetic agent carbachol induces headache in healthy subjects. Cephalalgia 29:258-268. doi:10.1111/j.14682982.2008.01715.x

65. Petersen KA, Birk S, Kitamura K, Olesen J (2009) Effect of adrenomedullin on the cerebral circulation: relevance to primary headache disorders. Cephalalgia 29:23-30. doi:10.1111/j.14682982.2008.01695.x

66. Lassen LH, Christiansen I, Iversen HK, Jansen-Olesen I, Olesen J (2003) The effect of nitric oxide synthase inhibition on histamine induced headache and arterial dilatation in migraineurs. Cephalalgia 23:877-886. doi:10.1046/j.1468-2982.2003.00586.x 
67. Burnstein R, Jakubowski M (2005) Unitary hypothesis for multiple triggers of the pain and strain of migraine. J Comp Neurol 493:9-14. doi:10.1002/cne.20688

68. Hansen JM, Petersen J, Wienecke T, Olsen KS, Jensen LT, Ashina M (2009) Sumatriptan does not change calcitonin generelated peptide in the cephalic and extracephalic circulation in healthy volunteers. J Headache Pain 10:85-91. doi:10.1007/ s10194-009-0102-x

69. Williamson DJ, Hargreaves RJ, Hill RG, Shepheard SL (1997) Sumatriptan inhibits neurogenic vasodilation of dural blood vessels in the anaesthetized rat-intravital microscope studies. Cephalalgia 17:525-531. doi:10.1046/j.1468-2982.1997.1704525.x

70. Munoz-Islas E, Gupta S, Jimenez-Mena LR, Lozano-Cuenca J, Sanchez-Lopez A, Centurion D, Mehrotra S, Maassen Van Den Brink A, Villalon CM (2006) Donitriptan, but not sumatriptan, inhibits capsaicin-induced canine external carotid vasodilatation via 5- $\mathrm{HT}_{1 \mathrm{~B}}$ rather 5-HT $1 \mathrm{D}$ receptors. Br J Pharmacol 149:82-91. doi:10.1038/sj.bjp.0706839

71. Sheykhzade M, Nyborg NC (2004) Homologous desensitization of calcitonin gene-related peptide-induced relaxation in rat intramural coronary arteries. Eur J Pharmacol 484:91-101. doi: 10.1016/j.ejphar.2003.10.052

72. Ebersberger A, Ringkamp M, Reeh PW, Handwerker HO (1997) Recording from brain stem neurons responding to chemical stimulation of subarachnoid space. J Neurophysiol 77:3122-3133

73. Edvinsson L, Tfelt-Hansen P (2008) The blood-brain barrier in migraine treatment. Cephalalgia 28:1245-1258. doi:10.1111/j. 1468-2982.2008.01675.x

74. Suzuki R, Rygh LJ, Dickenson AH (2004) Bad news from the brain: descending 5-HT pathways that control spinal pain processing. Trends Pharmacol Sci 25:613-617. doi:10.1016/j. tips.2004.10.002

75. Mason P (2005) Deconstructing endogenous pain modulation. J Neurophysiol 94:1659-1663. doi:10.1152/jn.00249.2005

76. Benarroch EE (2008) Descending monoaminergic pain modulation: Bidirectional control and clinical relevance. Neurology 71:217-221. doi:10.1212/01.wnl.0000318225.51122.63

77. Carlson JD, Maire JJ, Martenson ME, Heinricher MM (2007) Sensitization of pain-modulating neurons in the rostral ventromedial medulla after peripheral nerve injury. J Neurosci 27:13222-13231. doi:10.1523/JNEUROSCI.3715-07.2007

78. Zhao Z-Q, Chiechio S, Sun Y-G, Zhang K-H, Zhao C-S, Scott M, Johnson RL, Deneris ES, Renner KJ, RW Gereau IV, Chen Z-F (2007) Mice lacking central serotonergic neurons show enhanced inflammatory pain and an impaired analgesic response to antidepressant drugs. J Neurosci 27:6045-6053. doi: 10.1523/JNEUROSCI.1623-07.2007

79. Zhao Z-Q, Gao Y-J, Sun Y-G, Zhao C-S, Gereau RW IV, Chen Z-F (2007) Central serotonergic neurons are differentially required for opioid analgesia but not for morphine tolerance or morphine reward. Proc Natl Acad Sci USA 104:14519-14524. doi:10.1073/pnas.0705740104

80. Moja PL, Cusi C, Sterzi RR, Canepari C (2007) Selective serotonin re-uptake inhibitors (SSRIs) for preventing migraine and tension-type headache (review). The Cochrane Library 4:1-50

81. Sicuteri F, Boccuni M, Fanciullacci M, Gatto G (1983) Naloxone effectiveness on spontaneous and induced perceptive disorders in migraine. Headache 23:179-183. doi:10.1111/j.15264610.1983.hed2304179.x

82. Nicolodi M (1996) Differential sensitivity to morphine challenge in migraine sufferers and headache-exempt subjects. Cephalalgia 16:297-304. doi:10.1046/j.1468-2982.1996.1605297.x

83. Saper JR, Lake AE III (2008) Continuous opioid therapy (COT) is rarely advisable for refractory chronic daily headache: limited efficacy, risks, and proposed guidelines. Headache 48:838-849. doi:10.1111/j.1526-4610.2008.01153.x
84. Panconesi A, Anselmi B, Franchi G (1995) Increased adverse effects of opiates in migraine patients. Cephalalgia 15:159-160

85. Friedman BW, Kapoor A, Friedman MS, Hochberg ML, Rowe BH (2008) The relative efficacy of meperidine for the treatment of acute migraine: a meta-analysis of randomized controlled trials. Ann Emerg Med 52:705-713. doi:10.1016/j. annemergmed.2008.05.036

86. Ross JR, Riley J, Taegetmeyer AB, Sato H, Gretton S, du Bois RM, Welsh KI (2008) Genetic variation and response to morphine in cancer patients: catechol- $O$-methyltransferase and multidrug resistance-1 gene polymorphisms are associated with central side effects. Cancer 112:1390-1403. doi:10.1002/cncr.23292

87. Coppola G, Pierelli F, Schoenen J (2008) Habituation and migraine. Neurobiol Learn Mem. doi:10.1016/j.nlm.2008.07.006

88. Weiller C, May A, Limmroth V, Juptner M, Kaube H, Schayck RV, Coenen HH, Diener HC (1995) Brain stem activation in spontaneous human migraine attacks. Nat Med 1:658-660. doi: 10.1038/nm0795-658

89. Bahra A, Matharu MS, Buchel C, Franckowiak RS, Goadsby PJ (2001) Brainstem activation specific to migraine headache. Lancet 357:1016-1017. doi:10.1016/S0140-6736(00)04250-1

90. Afridi SK, Giffin NJ, Kaube H, Friston KJ, Ward NS, Frackowiak RSJ, Goadsby PJ (2005) A positron enission tomographic study in spontaneous migraine. Arch Neurol 62:12701275. doi:10.1001/archneur.62.8.1270

91. Sakai Y, Dobson C, Diksic M, Aubè M, Hamel E (2008) Sumatriptan normalizes the migraine attack-related increase in brain serotonin synthesis. Neurology 70:431-439. doi: 10.1212/01.wnl.0000299095.65331.6f

92. Lothe A, Merlet I, Demarquay G, Costes N, Ryvlin P, Mauguière $\mathrm{F}$ (2008) Interictal brain $5-\mathrm{HT}_{1 \mathrm{~A}}$ receptors binding in migraine without aura: a ${ }^{18} \mathrm{~F}$-MPPF-PET study. Cephalalgia 28:1282-1291. doi:10.1111/j.1468-2982.2008.01677.x

93. De Tommaso M, Lo Sito L, Di Fruscolo O, Sardaro M, Prudenzano MP, Lamberti P, Livrea P (2005) Lack of habituation of nociceptive evoked responses and pain sensitivity during migraine attack. Clin Neurophysiol 116:1254-1264. doi: 10.1016/j.clinph.2005.02.018

94. Bingel U, Schoell E, Herken W, Buchel C, May A (2007) Habituation to painful stimulation involves the antinociceptive system. Pain 131:21-30. doi:10.1016/j.pain.2006.12.005

95. Moulton EA, Burstein R, Tully S, Hargreaves R, Becerra L, Borsook D (2008) Interictal dysfunction of a brainstem descending modulatory center in migraine patients. PLOS ONE. doi:10.1371/journal.pone.0003799

96. Brighina F, Palermo A, Fierro B (2009) Cortical inhibition and habituation to evoked potentials: relevance for pathophysiology of migraine. J Headache Pain 10:77-84. doi:10.1007/s10194008-0095-x

97. Goadsby PJ (2007) Recent advances in understanding migraine mechanisms, molecules and therapeutics. Trends Mol Med 13:39-44. doi:10.1016/j.molmed.2006.11.005

98. Lambert GA, Hoskin KL, Zagami AS (2008) Cortico-NRM influences on trigeminal neuronal sensation. Cephalalgia 28:640-652. doi:10.1111/j.1468-2982.2008.01572.x

99. Dodick DW (2008) Examining the essence of migraine-Is it the blood vessel or the brain? A debate. Headache 48:661-667

100. Rothrock JF (2008) "Outside-In" vs "Inside-Out": revisiting migraine's vascular hypothesis. Headache 48:1409-1410. doi: 10.1111/j.1526-4610.2008.01276.x

101. Cutrer FM, Charles A (2008) The neurogenic basis of migraine. Headache 48:1411-1414. doi:10.1111/j.1526-4610.2008.01277.x

102. Dahl E, Edvinsson L (1988) Anatomical organization of cerebral and extracerebral vasculature. In: Olesen J, Edvinsson L (eds) Basic mechanisms of headache. Elsevier, Amsterdam, pp 27-47 